\title{
Direct Evidence for As as a Zn-Site Impurity in ZnO
}

\author{
U. Wahl, ${ }^{1,2, *}$ E. Rita, ${ }^{1,2}$ J. G. Correia, ${ }^{1,2,3}$ A. C. Marques, ${ }^{2,3}$ E. Alves, ${ }^{1,2}$ and J. C. Soares ${ }^{2}$ \\ (ISOLDE Collaboration) $^{3}$ \\ ${ }^{1}$ Instituto Tecnológico e Nuclear, Estrada Nacional 10, 2686-953 Sacavém, Portugal \\ ${ }^{2}$ Centro de Física Nuclear da Universidade de Lisboa, Avenida Professor Gama Pinto 2, 1649-003 Lisboa, Portugal \\ ${ }^{3}$ CERN-PH, 1211 Genève 23, Switzerland
}

(Received 29 July 2005; published 15 November 2005)

\begin{abstract}
Arsenic has been reported in the literature as one of the few $p$-type dopants in the technologically promising II-VI semiconductor $\mathrm{ZnO}$. However, there is an ongoing debate whether the $p$-type character is due to As simply replacing $\mathrm{O}$ atoms or to the formation of more complicated defect complexes, possibly involving As on $\mathrm{Zn}$ sites. We have determined the lattice location of implanted $\mathrm{As}$ in $\mathrm{ZnO}$ by means of conversion-electron emission channeling from radioactive ${ }^{73} \mathrm{As}$. In contrast to what one might expect from its nature as a group $\mathrm{V}$ element, we find that As does not occupy substitutional $\mathrm{O}$ sites but in its large majority substitutional $\mathrm{Zn}$ sites. Arsenic in $\mathrm{ZnO}$ (and probably also in $\mathrm{GaN}$ ) is thus an interesting example for an impurity in a semiconductor where the major impurity lattice site is determined by atomic size and electronegativity rather than its position in the periodic system.
\end{abstract}

PACS numbers: $61.72 . \mathrm{Vv}$

The textbook example of doping a semiconductor with acceptors or donors is to substitute host atoms by elements from neighboring columns of the periodic system. In elemental semiconductors such as silicon or germanium, elements from the 3rd or 5th column of the periodic table act as acceptors or donors when replacing the group IV host atoms. In compound semiconductors usually chemical similarities and electronegativity determine the preferred lattice position and hence the doping character of an impurity. For instance, the III-V compound GaAs can be doped $p$-type by the group II alkaline earths $\mathrm{Be}$ and $\mathrm{Mg}$ or by the group IIa metals $\mathrm{Zn}, \mathrm{Cd}$, and $\mathrm{Hg}$, which substitute for $\mathrm{Ga}$, while $n$-type doping is achieved by the group VI chalcogens $\mathrm{S}, \mathrm{Se}$, and $\mathrm{Te}$, which replace As [1-3]. The group IV elements are amphoteric in GaAs; i.e., they may occupy both cation or anion sites, and both donor and acceptor character has been reported [1]. However, while $\mathrm{Si}, \mathrm{Ge}, \mathrm{Sn}$, and $\mathrm{Pb}$ mainly replace $\mathrm{Ga}$ and are therefore more commonly found as donors, $\mathrm{C}$ preferentially replaces As and the acceptor state dominates [4-6]. On the other hand, it has been estimated that around $10 \%$ of Bi impurities occupy Ga sites in GaAs, acting as double donors [7] and thus illustrating the competing characteristics of $\mathrm{Bi}$ as a metal and a group $\mathrm{V}$ element. As was pointed out by Desnica [8] and is illustrated in this Letter, size matching between the atomic radii of impurities and host atoms acts as an additional important criterion determining the lattice sites of foreign atoms in semiconductors and hence must be taken into account when assessing the nature of their role as acceptors or donors.

The II-VI compound $\mathrm{ZnO}$ has a large potential for many applications in optoelectronics and could rival GaN, which is currently the material of choice for the production of blue light emitting diodes and lasers. It is well known that in all wide-band-gap semiconductors (WBGS) only one type of doping, either $n$-type or $p$-type, is easily achieved. The general origin for the doping difficulties in WBGS seems to be the spontaneous creation of certain amphoteric defects, which limits the range of available positions of the Fermi level in thermal equilibrium $[9,10]$. While $n$-type $\mathrm{ZnO}$ can be realized by means of substituting $\mathrm{Zn}$ with $\mathrm{Al}$, $\mathrm{Ga}$, or In [11], finding a suitable acceptor has turned out to be an extremely difficult task. The only impurities for which successful $p$-type doping has been reported are the group $\mathrm{V}$ elements $\mathrm{N}$ and $\mathrm{P}$ ([11] and references therein) and, more recently, also As [12-17] and $\mathrm{Sb}$ [18]. However, due to the large mismatch of the ionic radii of $\mathrm{P}^{3-}(2.12 \AA)$, $\mathrm{As}^{3-}(2.22 \AA)$, and $\mathrm{Sb}^{3-}(2.45 \AA)$ with $\mathrm{O}^{2-}(1.38 \AA)$ it was argued that those impurities should have a low solubility substituting for $\mathrm{O}$ in $\mathrm{ZnO}$ [11]. This is also backed by theoretical calculations which suggest that these elements should be more stable on $\mathrm{Zn}$ sites and, furthermore, that the energy levels of $\mathrm{P}, \mathrm{As}$, and $\mathrm{Sb}$ replacing $\mathrm{O}$ are located deep in the band gap of $\mathrm{ZnO}[19,20]$. In order to explain the $p$-type character of $\mathrm{ZnO}$ following As doping, it was suggested that the acceptor action is actually due to $\mathrm{As}_{\mathrm{Zn}}-$ $2 V_{\mathrm{Zn}}$ complexes, where an As atom occupies a $\mathrm{Zn}$ "antisite" and is decorated with two $\mathrm{Zn}$ vacancies [20]. Considerable arguments are thus pointing against the observed $p$-type conductivity being due to $\mathrm{P}, \mathrm{As}$, and Sb acting, according to their chemical nature as group $\mathrm{V}$ impurities, as simple "chemical" acceptors on $\mathrm{O}$ sites. However, so far no experimental method has been able to provide reliable knowledge on the lattice sites of these elements in $\mathrm{ZnO}$.

In this work we have determined the lattice location of radioactive ${ }^{73} \mathrm{As}$ in single-crystalline $\mathrm{ZnO}$ by means of the emission channeling technique [21]. Emission channeling is based on the fact that charged particles from nuclear 
decay ( $\alpha, \beta^{-}, \beta^{+}$, conversion electrons) experience channeling or blocking effects along major crystallographic axes and planes. The resulting anisotropic emission yield from the crystal surface characterizes the lattice site occupied by the probe atoms during decay. The isotope ${ }^{73} \mathrm{As}$ $\left(t_{1 / 2}=80.3 d\right)$ decays by means of electron capture into the excited state ${ }^{73 \mathrm{~m}} \mathrm{Ge}$, which deexcites with a half-life of $499 \mathrm{~ms}$ into the ground state via the emission of gammas or conversion electrons. Note that only a nuclear recoil of $0.54 \mathrm{eV}$ is transferred to the ${ }^{73} \mathrm{Ge}$ atom during the decay, which is considerably smaller than the atomic displacement energy of $57 \mathrm{eV}$ reported for $\mathrm{ZnO}$ [22], thus assuring that the lattice site of ${ }^{73 \mathrm{~m}} \mathrm{Ge}$ is not substantially altered with respect to ${ }^{73}$ As.

A commercially available $\mathrm{ZnO}$ [0001] single crystal (Eagle Picher Technologies), grown by seeded chemical vapor transport and polished on the $\mathrm{O}$ face, was implanted at room temperature with ${ }^{73} \mathrm{As}$ at $60 \mathrm{keV}$ energy to a dose of $2.0 \times 10^{13} \mathrm{~cm}^{-2}$. The production of ${ }^{73} \mathrm{As}$ and the implantation were performed at CERN's on-line isotope separator facility ISOLDE. A $7^{\circ}$ angle from the surface normal was applied in order to minimize the fraction of ${ }^{73}$ As atoms channeled during implantation and to provide a welldefined depth profile (projected range $234 \AA$ and straggling $100 \AA$ ). The angular emission patterns of the $42.3 \mathrm{keV}$ and $52.1 \mathrm{keV}$ conversion electrons from the ${ }^{73} \mathrm{As} \rightarrow{ }^{73} \mathrm{Ge}$ decay were recorded around the [0001], [11102], [11101], and [2113] directions by means of a position-sensitive Si detector [23]. These measurements were carried out at room temperature in the as-implanted state and following $10 \mathrm{~min}$ in situ vacuum annealing steps at $300{ }^{\circ} \mathrm{C}, 600^{\circ} \mathrm{C}$, and $900{ }^{\circ} \mathrm{C}$.

The evaluation of the probe atom lattice location was performed by quantitatively comparing the experimental patterns with theoretical ones, using the two-dimensional fit procedure outlined in Ref. [23]. In the fit procedure, we considered theoretical patterns resulting from emitter atoms at substitutional $\mathrm{Zn}$ sites $\left(\mathrm{S}_{\mathrm{Zn}}\right)$ and $\mathrm{O}$ sites $\left(\mathrm{S}_{\mathrm{O}}\right)$ with varying rms displacements, the main interstitial sites (cf. Fig. 1), and a diversity of interstitial sites resulting from displacements along or basal to the $c$ axis. The theoretical emission channeling patterns were calculated by means of the "many beam" theory of electron diffraction in single crystals [21]. Details with respect to the structural properties of $\mathrm{ZnO}$ used in the simulations have been given previously $[24,25]$.

The angle dependent electron emission yield around the [0001] direction, following $300^{\circ} \mathrm{C}$ annealing, is shown in Fig. 2(a). From the fact that channeling is observed in the axial direction and within the major planes, it is clear that the majority of emitter atoms are located within the atomic rows along the $c$ axis. The best fit [Fig. 2(e)] was obtained for $94 \%$ of emitter atoms with a rms displacement of $u_{1}=$ $0.13 \AA$ from the $c$ axis, and $6 \%$ of emitter atoms contributing with isotropic electron yield. However, since both substitutional $\mathrm{Zn}$ sites $\mathrm{S}_{\mathrm{Zn}}$ and substitutional $\mathrm{O}$ sites $\mathrm{S}_{\mathrm{O}}$ as

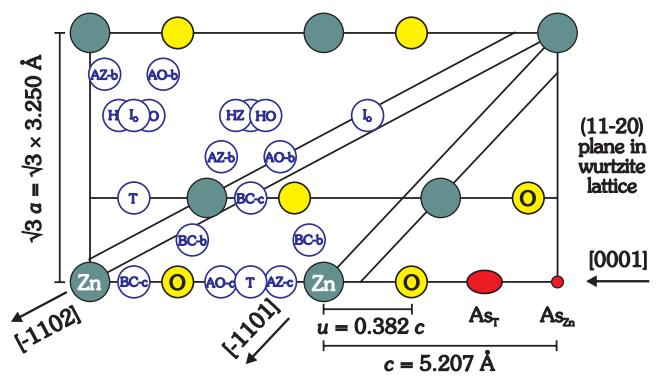

FIG. 1 (color online). The $(11 \overline{2} 0)$ plane in the wurtzite lattice, showing the location of substitutional $\mathrm{Zn}$ sites, substitutional $\mathrm{O}$ sites, bond center (BC), antibonding $\mathrm{Zn}$ (AZ), antibonding $\mathrm{O}$ $(\mathrm{AO})$, interstitial "octahedral" $\left(\mathrm{I}_{\mathrm{O}}\right)$, "tetrahedral" $(\mathrm{T})$, and "hexagonal" (HZ and HO). "-c" denotes sites within and " $-b$ " basal to the $c$ axis. The pairs of rows of $\mathrm{Zn}$ atoms along the [1102] and [1101] directions are indicated while the corresponding rows of $\mathrm{O}$ atoms are not marked. The [2113] axis (not shown) is a direction similar to [1102] and [1101] but located within the (0110) plane. The small red (gray) circle and larger ellipse in the lower right-hand corner indicate the estimated experimental error in determining the location of emitter atoms on substitutional $\mathrm{Zn}$ and interstitial $T$ sites.

well as a variety of interstitial sites are located along the $c$ axis (Fig. 1), the [0001] pattern alone does not allow one to unambiguously determine the lattice location, and the electron channeling patterns around additional crystal directions with well-separated rows of $\mathrm{Zn}$ and $\mathrm{O}$ atoms have

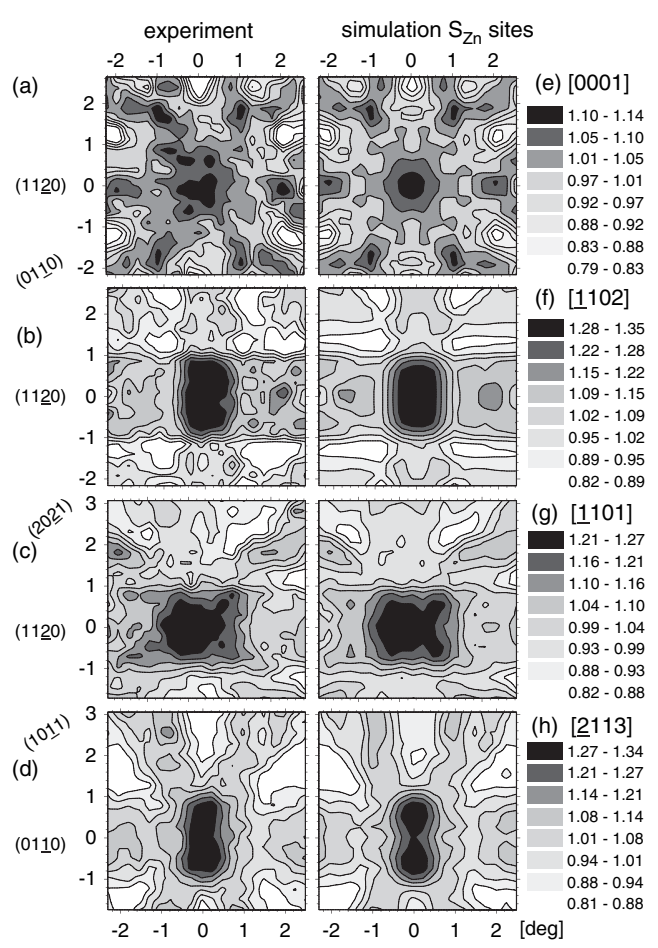

FIG. 2. Angular distribution of conversion electrons from ${ }^{73} \mathrm{As} \rightarrow{ }^{73} \mathrm{Ge}$ in $\mathrm{ZnO}$ following $300{ }^{\circ} \mathrm{C}$ annealing around the [0001] (a), [11102] (b), [11101] (c), and [2113] (d) axis. (e)(h) Best fits of the channeling patterns for each direction, corresponding to $90(8) \%$ of probe atoms at $\mathrm{S}_{\mathrm{Zn}}$ sites. 
to be taken into account. Figures 2(b)-2(d) show the emission channeling patterns around the [11102], [11101], and [ $\overline{2} 113]$ directions. Figures $2(\mathrm{f})-2(\mathrm{~h})$ represent the best two-fraction fits of the corresponding theoretical yields, obtained by considering only emitter atoms on substitutional $\mathrm{S}_{\mathrm{Zn}}$ sites and varying their $\mathrm{rms}$ displacement $u_{1}$ and emitter atoms on random sites. Note that the random fraction accounts for emitter atoms on sites contributing with isotropic emission yield, which are sites of very low crystal symmetry or in heavily damaged surroundings. The rms displacements from $S_{Z n}$ sites which gave the best fit were $0.11,0.13$, and $0.11 \AA$, perpendicular to the [11102], [1101], and [2113] directions, respectively, and the corresponding fractions on $\mathrm{S}_{\mathrm{Zn}}$ sites were $83 \%, 98 \%$, and $91 \%$. We conclude that $90(8) \%$ of emitter atoms occupied the substitutional $\mathrm{Zn}$ sites with a rms displacement of $0.11-0.13 \AA$.

Major fractions of emitter atoms on other lattice sites can be ruled out. The theoretical channeling patterns from emitter atoms on substitutional $\mathrm{O}$ sites and tetrahedral interstitial $T$ sites, for instance, are shown in Fig. 3 and are clearly incompatible with the experimental patterns. We tried including additional fractions of emitter atoms on $\mathrm{S}_{\mathrm{O}}$ sites, but the resulting fractions were at maximum a few percent, with the fraction on substitutional $\mathrm{Zn}$ sites remaining around $90 \%$.

Figures 4(a)-4(d) show the emission channeling patterns following vacuum annealing at $900{ }^{\circ} \mathrm{C}$. Note that these patterns were measured with less statistics than those shown in Fig. 2 and with a somewhat different orientation of the sample towards the detector. The [0001] pattern exhibited a small decrease in anisotropy following the $900{ }^{\circ} \mathrm{C}$ annealing step, with the fit showing that $\sim 83 \%$ of emitter atoms were still located within the $c$-axis atomic

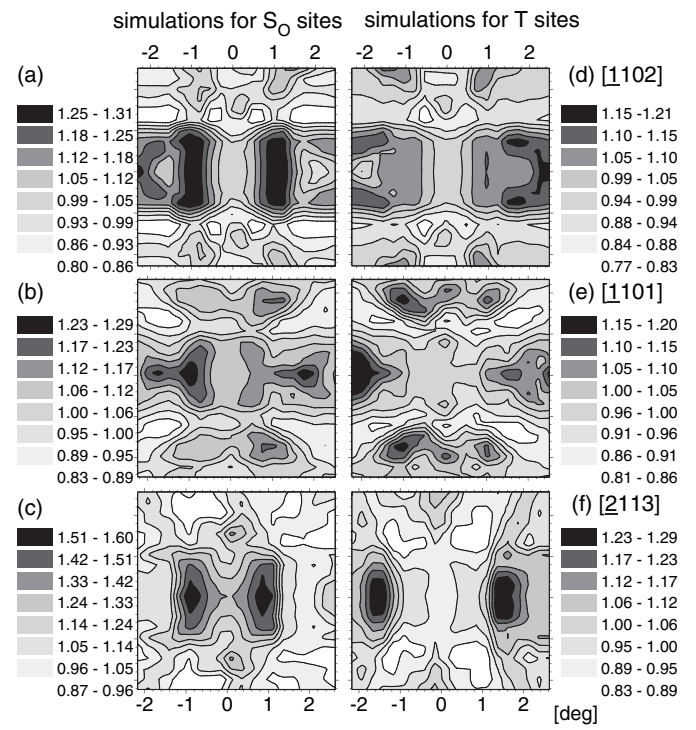

FIG. 3. Theoretical emission channeling patterns for $100 \%$ of emitter atoms on $\mathrm{S}_{\mathrm{O}}$ sites (a)-(c) and $100 \%$ on $T$ sites (d)-(f). The [0001] patterns for both sites are not shown since they are identical to the pattern for substitutional $\mathrm{Zn}$ sites. rows. However, for the other three directions, the anisotropy decreased considerably, indicating that some fraction of the emitter atoms no longer occupied the substitutional $\mathrm{Zn}$ sites, which was fully confirmed by the fit results. The introduction of an additional fraction of emitter atoms at or within a distance of $0.4 \AA$ from interstitial $T$ sites improved the [1102], [1101], and [ $\overline{2} 113] \chi^{2}$ fit by $13 \%, 12 \%$, and $55 \%$, respectively, with best fits obtained for $62(4) \%$ on substitutional $\mathrm{Zn}$ sites and $28(3) \%$ at or close to interstitial $T$ sites.

Figure 5 shows the fractions of emitter atoms on substitutional $\mathrm{Zn}$ and interstitial $T$ sites as a function of annealing temperature. Already in the as-implanted state, $73 \%$ of the emitter atoms were found on $\mathrm{S}_{\mathrm{Zn}}$ sites, and we have indications that a fraction of the remaining atoms is located on interstitial sites out of the $c$ axis, but we were not able to identify which interstitial site it might be. Upon annealing at $300^{\circ} \mathrm{C}$ the fraction on substitutional $\mathrm{Zn}$ sites reached a maximum around $90 \%$, decreasing somewhat following the $600^{\circ} \mathrm{C}$ anneal, while after $900^{\circ} \mathrm{C}$ annealing $\sim 30 \%$ occupied the interstitial $T$ sites. The rms displacements from the ideal $\mathrm{Zn}$ positions were in all cases around 0.07-0.17 $\AA$, i.e., somewhat larger than the thermal vibration amplitude of the $\mathrm{Zn}$ atoms $u_{1}(\mathrm{Zn})=0.080 \AA$.

Our results clearly show that the majority of implanted As does not occupy substitutional $\mathrm{O}$ sites. Hence, if the acceptors in As-doped $\mathrm{ZnO}$ [12-17] are actually simple

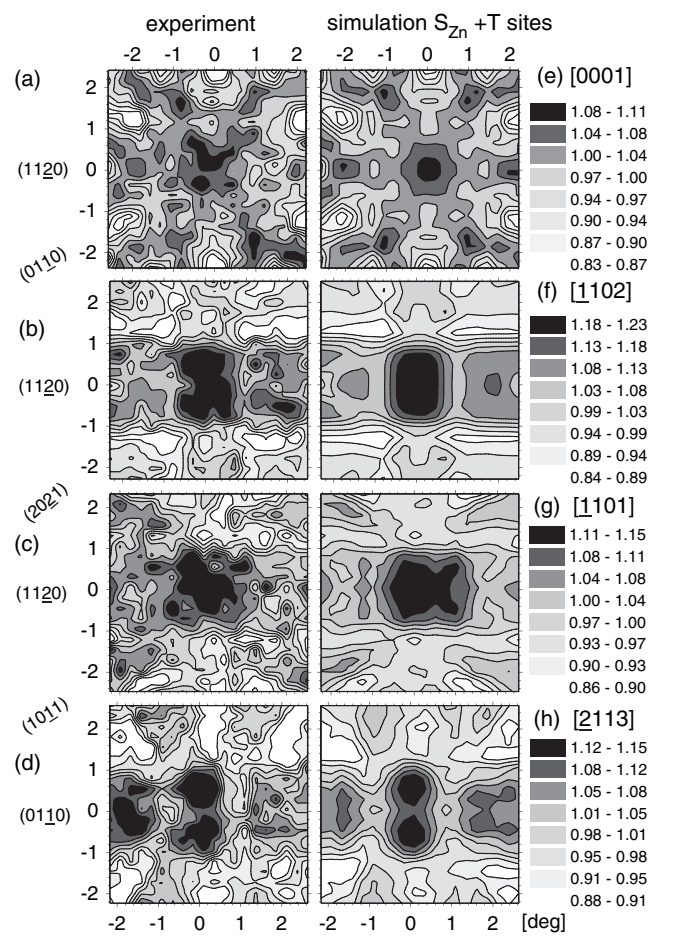

FIG. 4. (a)-(d) ${ }^{73} \mathrm{As} \rightarrow{ }^{73} \mathrm{Ge}$ conversion-electron emission channeling patterns following $900{ }^{\circ} \mathrm{C}$ annealing in vacuum. (e)-(h) The best fits correspond to $61(8) \%$ of As probe atoms at substitutional $\mathrm{S}_{\mathrm{Zn}}$ sites and $27(3) \%$ at or close to interstitial $T$ sites. 


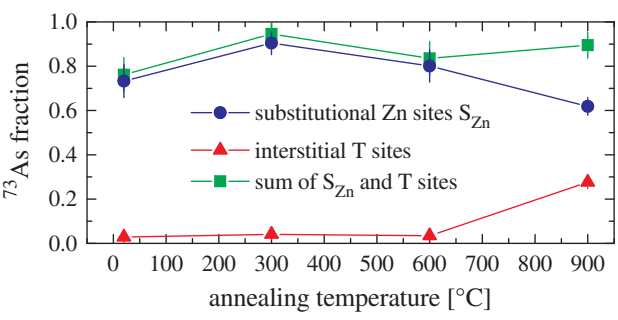

FIG. 5 (color online). Fractions of probe atoms on substitutional $\mathrm{Zn}$ and interstitial $T$ sites and the sum of both as a function of annealing temperature.

chemical $\mathrm{As}_{\mathrm{O}}$ acceptors, these probably represent only a small minority and this doping approach should therefore not be likely to lead to highly $p$-type $\mathrm{ZnO}$. However, our results are compatible with the suggestion of Ref. [20] that the acceptor character of As is related to defect complexes involving $\mathrm{Zn}_{\mathrm{As}}$, e.g., $\mathrm{As}_{\mathrm{Zn}}-2 V_{\mathrm{Zn}}$. Two structures were proposed for these complexes. If the complex is triply negatively charged, As should be fourfold O coordinated and remain relatively close to the ideal $\mathrm{Zn}$ lattice position. In a neutral complex, on the other hand, As should be fivefold $\mathrm{O}$ coordinated and relax along the $c$ axis, around 0.4$0.5 \AA$ or halfway from the ideal $\mathrm{Zn}$ position towards the antibonding $\mathrm{Zn}$ site (AZ-c in Fig. 1). Since the channeling method is not particularly sensitive to the direct surroundings of the probe atoms, the presence of one or several $\mathrm{Zn}$ vacancies close to ${ }^{73} \mathrm{As}$ would not influence our results unless it causes a significant displacement of ${ }^{73}$ As or the daughter nucleus ${ }^{73 \mathrm{~m}} \mathrm{Ge}$. In that respect, it should also be taken into account that the lattice location experiments take place when the ${ }^{73}$ As probe atoms have decayed to ${ }^{73 m} \mathrm{Ge}$, which can cause some relaxation in the atomic structure of the complexes. The site change to $T$ sites $\left(1.6 \AA\right.$ from $\left.\mathrm{S}_{\mathrm{Zn}}\right)$ observed for part of the probe atoms following $900{ }^{\circ} \mathrm{C}$ vacuum annealing indicates that $\mathrm{O}$-poor annealing conditions could alter the nature of the complexes.

While many examples of minority antisite defects in semiconductors have already been reported, e.g., $\mathrm{As}_{\mathrm{Ga}}$ [1] or $\mathrm{Bi}_{\mathrm{Ga}}$ [7] in $\mathrm{GaAs}$, the case of As in $\mathrm{ZnO}$ is different since it concerns an impurity where even the most common lattice site is contrary to what one would simply expect from its position in the periodic system. The $\mathrm{Zn}$-site character of As can be explained from the large size mismatch of $\mathrm{As}^{3-}$ with $\mathrm{O}^{2-}$ but the good match between $\mathrm{As}^{3+}$ and $\mathrm{Zn}^{2+}(0.58 \AA$ vs $0.60 \AA)$, its electronegativity of 2.0 , which is closer to $\mathrm{Zn}$ (1.6) than to $\mathrm{O}$ (3.5), and its character as a semimetal, all of which make it energetically favorable for the As impurity to be incorporated on $\mathrm{Zn}$ sites [19,20]. A similar site preference was suggested to exist for P, As [26], and $\mathrm{Sb}$ [8] in $\mathrm{GaN}$, which would explain the considerable difficulties in growing stoichiometric ternary compounds such as $\mathrm{GaAs}_{x} \mathrm{~N}_{1-x}$ for small values of $x$. Also, the possible donor elements S, Se, and Te [27] in GaN are likely to suffer from the same effect.

This work was supported by the Portuguese Foundation for Science and Technology (FCT, Project No. PDCT-FP-
FNU-50145-2003) and by the European Union (Large Scale Facility Contract No. HPRI-CT-1999-00018). E. R., A.C.M., and U.W. acknowledge support from FCT, Portugal.

*Corresponding author.

Electronic address: uwahl@itn.pt

[1] U. Kaufmann and J. Schneider, Adv. Electron. Electron Phys. 58, 81 (1982).

[2] P. D. Greene, Solid State Commun. 9, 1299 (1971).

[3] O. P. Ka and P. J. Fons, Appl. Phys. Lett. 67, 1465 (1995).

[4] R. Newman, Mater. Sci. Eng. B 66, 39 (1999).

[5] J. Nishizawa, S. Shonizaki, and K. Ishida, J. Appl. Phys. 44, 1638 (1973).

[6] U. Willke, D. K. Maude, J. M. Sallese, M. L. Fille, B. el Jani, P. Gibart, and J. C. Portal, Appl. Phys. Lett. 62, 3467 (1993).

[7] M. Kunzer, W. Jost, U. Kaufmann, H. M. Hobgood, and R. N. Thomas, Phys. Rev. B 48, 4437 (1993).

[8] U. V. Desnica, Solid State Commun. 69, 411 (1989).

[9] W. Walukiewicz, Physica (Amsterdam) 302B, 123 (2001).

[10] S. B. Zhang, J. Phys. Condens. Matter 14, R881 (2002).

[11] S. J. Pearton, D. P. Norton, K. Ip, Y. W. Heo, and T. Steiner, J. Vac. Sci. Technol. B 22, 932 (2004).

[12] Y. R. Ryu, S. Zhu, D. C. Look, J. M. Wrobel, H. M. Jeong, and H. W. White, J. Cryst. Growth 216, 330 (2000).

[13] Y. R. Ryu, T. S. Lee, and H. W. White, Appl. Phys. Lett. 83, 87 (2003).

[14] Y. R. Ryu, T. S. Lee, J.H. Leem, and H. W. White, Appl. Phys. Lett. 83, 4032 (2003).

[15] D. C. Look, G. M. Renlund, R. H. Burgener II, and J. R. Sizelove, Appl. Phys. Lett. 85, 5269 (2004).

[16] W. Lee, M. Jeong, and J. Myoung, Appl. Phys. Lett. 85, 6167 (2004).

[17] V. Vaithianathan, B. Lee, and S. S. Kim, Appl. Phys. Lett. 86, 062101 (2005).

[18] T. Aoki, Y. Shimizu, A. Miyake, A. Nakamura, Y. Nakanishi, and Y. Hatanaka, Phys. Status Solidi B 229, 911 (2002).

[19] C. H. Park, S. B. Zhang, and S.H. Wei, Phys. Rev. B 66, 073202 (2002).

[20] S. Limpijumnong, S. B. Zhang, S. H. Wei, and C. H. Park, Phys. Rev. Lett. 92, 155504 (2004).

[21] H. Hofsäss and G. Lindner, Phys. Rep. 201, 121 (1991).

[22] J. M. Meese, IEEE Trans. Nucl. Sci. 19, 237 (1972).

[23] U. Wahl, J. G. Correia, A. Czermak, S. G. Jahn, P. Jalocha, J. G. Marques, A. Rudge, F. Schopper, J.C. Soares, A. Vantomme, and P. Weilhammer (ISOLDE Collaboration), Nucl. Instrum. Methods Phys. Res., Sect. A 524, 245 (2004).

[24] U. Wahl, E. Rita, J. G. Correia, E. Alves, and J. P. Araújo (ISOLDE Collaboration), Appl. Phys. Lett. 82, 1173 (2003).

[25] U. Wahl, E. Rita, J. G. Correia, E. Alves, and J. C. Soares (ISOLDE Collaboration), Phys. Rev. B 69, 012102 (2004).

[26] C. G. Van De Walle and J. Neugebauer, Appl. Phys. Lett. 76, 1009 (2000).

[27] A. Seppälä, E. Rauhala, and R. Grötzschel, J. Phys. D 34, 269 (2001). 